\title{
UJI PERFORMA MOTOR BENSIN BERBASIS PROGRAM LABVIEW
}

\author{
Nana Supriyana \\ Program Studi Teknik Mesin \\ Sekolah Tinggi Teknik Wiworotomo \\ Email: Nana.sttw@gmail.com \\ Mastur \\ Program Studi Teknik Mesin \\ Sekolah Tinggi Teknik Wiworotomo \\ Email: Masturpwt@gmail.com
}

\begin{abstract}
ABSTRAK
Performa motor bensin ditunjukan dalam data Torsi dan Daya, berbagai cara dilakukan untuk memperoleh data performa motor bensin mengukur output pada komponen crankshaft, temperatur saluran masuk dan saluran keluar ruang bakar dan temperatur lingkungan. Kegiatan penelitian bertujuan untuk memperoleh data performa pada motor bensin 4 langkah menggunakan software LabVIEW dan Data Aquisition menggunakan NI DAQ USB 6008 produk National Instrumen sebagai pengolah data. Penggunaan beberapa komponen seperti sensor putaran jenis induksi proximity, sensor temperatur dan sensor induksi tegangan tinggi, komponen penguat tegangan sensor dengan Roller Dynamometer Inertia tipe chassis. Hasil data performa motor bensin berupa Torsi dan Daya dapat terbaca pada alat uji dynamometer data Torsi mulai terbaca pada putaran 3750 RPM dengan nilai sekitar 10,65 Nm dan nilai maksimal pada putaran 7574 RPM sebesar 14,84 Nm sedangkan data Daya pada putaran 3750 sebesar 5,6 HP dan nilai maksimal pada putaran 8500 RPM dengan nilai sebesar 16,9 HP. Hasil penelitian tersebut memperlihatkan penggunaan software LabVIEW pada uji performa motor bensin tidak jauh berbeda dengan karakteristik yang dimiliki motor bensin.
\end{abstract}

Kata kunci: performa; labview; daya; torsi.

\begin{abstract}
Gasoline engine performance is shown in Torque and Power data, various methods are carried out to obtain gasoline engine performance data measuring the output of the crankshaft component, temperature of the inlet and outlet of the combustion chamber and ambient temperature. The research activity aims to obtain performance data on four stroke gasoline engine using LabVIEW software and aquicition data using NI DAQ USB 6008 National Instrument products as data processing. The use of several components such as proximity induction sensor rotation, temperature sensor and high voltage induction sensor, sensor voltage amplifier component with Roller Dynamometer Inertia chassis type. The results of gasoline engine performance data in the form of torque and power can be read on the torque data dynamometer test tool starting to read at a rotation of $3750 \mathrm{RPM}$ with a value of about $10.65 \mathrm{Nm}$ and maximum value at 7574 RPM rotation is $14.84 \mathrm{Nm}$ while the Power data at 3750 rounds is $5.6 \mathrm{HP}$ and the maximum value is at 8500 RPM rotation with a value of $16.9 \mathrm{HP}$. The results of the study show that the use of LabVIEW software on the gasoline engine performance test is not much different from the characteristics of a gasoline engine.
\end{abstract}

Keywords: performance; labview; power; torque.

\section{PENDAHULUAN}

Indikator performa kerjamotor bensin [1] dapat dipakai sebagai salah satu pertimbangan masyarakat untuk memilih dan menggunakan suatu motor bakar sebagai sumber tenaga. Indikator tersebut diantaranya Torsi, Daya dan Konsumsi bahan bakar spesifik, merupakan suatu besaran-besaran yang didapat dari pengukuran parameter kerja komponen suatu motor bakar. Beberapa parameter tersebut dipahami oleh banyak masyarakat sebagai penentu performa atau unjuk kerja motor bensin. Parameter Torsi suatu motor bakar diperoleh dari konversi energi termal (panas) hasil pembakaran campuran bahan bakar dengan udara di dalam ruang bakar yang menghasilkan tenaga dengan suhu dan tekanan tinggi, tenaga tersebut akan mendorong piston ke titik mati bawah dan disalurkan ke poros engkol (cranksahft) melalui batang piston dirubah menjadi energi mekanik oleh mekanisme cranksahft dan selanjutnya dihubungkan ke komponen 
Flywheel untuk menggerakan komponen pada sistem transmisi. Parameter Torsi didefinisikan sebagai besarnya momen putar yang terjadi pada output crankshaft motor bakar yaitu Flywheel akibat adanya pembebanan dengan sejumlah massa $(\mathrm{kg})$, sedangkan parameter Daya motor adalah besarnya kerja motor selama putaran dan waktu tertentu.

Berbagai cara dilakukan untuk memperoleh Indikator performa motor bakar seperti mengukur keluaran motor bakar pada poros engkol dengan cara sederhana yaitu dengan memberikan beban pengereman secara konvensional sampai dengan melakukan pengukuran menggunakan peralatan yang modern seperti perangkat lunak komputer (software), penggunaan beberapa sensor sebagai penghasil sinyal dan lain sebagainya. Hasil pengukuran keluaran motor bakar pada komponen crankshaft didapat suatu hubungan antara putaran crankshaft dengan Torsi serta putaran crankshaft dengan Daya motor [2], menunjukan bahwa Torsi dan Daya meningkat seiring dengan bertambahnya putaran crankshaft, namun setelah mencapai nilai maksimum, secara perlahan Torsi dan Daya mengalami penurunan walaupun putaran mesin terus bertambah.

Seiring dengan perkembangan teknologi, banyak penemuan baru diciptakan untuk membantu pekerjaan yang dilakukan oleh masyarakat salah satunya adalah program komputer atau software untuk pengolahan data [3]. Pada beberapa penerapan aplikasi tersebut satu diantaranya digunakan untuk mengukur performa motor bakar. Beberapa cara untuk melakukan uji performa motor bakar yang telah dilakukan masyarakat seperti menggunakan alat dynotest [4], dengan alat tersebut dapat diperoleh beberapa data parameter yang bisa menunjukan performa kerja suatu motor bakar, dan dengan memanfaatkan beberapa penemuan teknologi beberapa masukan yang dari sensor diolah menggunakan salah satu software yaitu software LabVIEW produk dari National Instrument (NI). Data Torsi dan Daya motor diperoleh dengan menggunakan beberapa persamaan matematik, persamaan matematik tersebut kemudian dimasukan dalam software LabVIEW sehingga mendapatkan hasil akhir data Torsi dan Daya motor kondisi real time, fasilitas block diagram yang telah disusun di dalamnya dengan persamaan matematik sehingga mendapatkan hasil akhir berupa angka yang bisa disimpan secara otomatis dengan bantuan data aquisition NI Daq secara real time dikomparasi dengan software LabVIEW [5][6][7]. Beberapa pertimbangan dalam aplikasi komponen sensor berupa alat pengukur suhu tinggi secara non-kontak dengan menggunakan sensor MLX90614 berbasis arduino dan LabVIEW adalah dapat menghasilkan pengukuran yang ditampilkan secara serial maupun berupa grafik serta hasil pengukuran suhu benda dapat dilakukan lebih cepat dibandingkan menggunakan sensor suhu LM35 [8].

Penggunaan Data Aquisition dari National Instrument mendapatkan hasil yang baik dengan penyimpangan $+2,25 \%$ [9] pada suatu pengujian performa motor bensin 4 langkah. Beberapa hasil penelitian terdahulu tersebut dapat disimpulkan bahwa penggunaan software LabVIEW untuk mengolah data didapat data secara realtime sehingga penulis melakukan uji coba penggunaan sotfware LabVIEW untuk mendapatkan data performa motor bensin 4 langkah seperti terlihat pada Gambar 1 suatu ilustrasi pengambilan data performa motor bakar dengan chassis dynamometer type inertia yang digunakan di laboratorium teknik sepeda motor Sekolah Tinggi Teknik Wiworotomo Purwokerto.

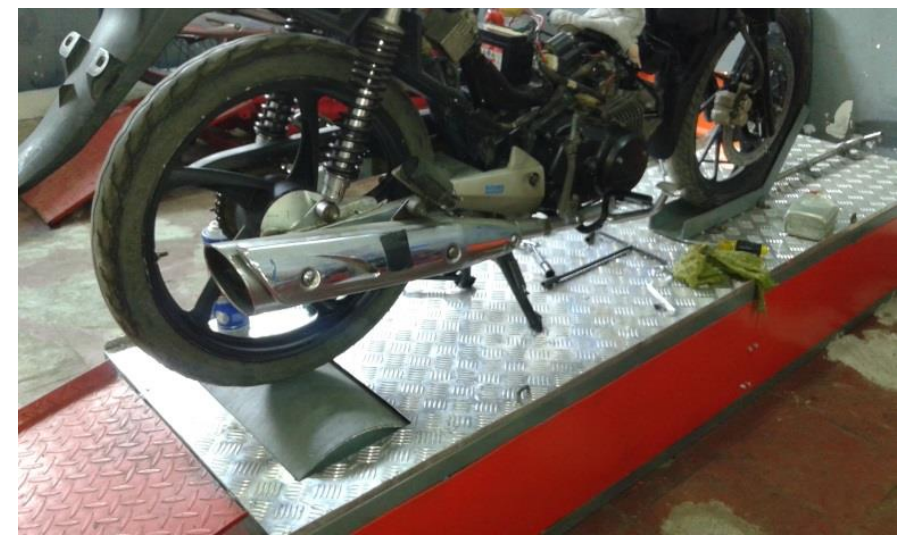

\section{Gambar 1. Proses Pengambilan Data Menggunakan Chassis Dynamometer Type}

Data performa suatu motor bensin seperti Torsi, Daya dan Konsumsi bahan bakar banyak digunakan oleh produsen maupun konsumen pengguna kendaraan, dengan indikator tersebut dapat diketahui kemampuan kerja motor bensin sebagai pertimbangan dalam penggunaannya. Tujuan kegiatan penelitian adalah melakukan pengambilan data dan pengolahan data performa motor bensin dengan menggunakan software LabVIEW, LabVIEW atau Laboratory Virtual Instrument Workbench produk dari National Instrument telah banyak digunakan oleh para peneliti maupun dunia industri untuk pengontrolan maupun pengolaha data secara real time. Program LabVIEW merupakan suatu program komputer berbasis bahasa 
pemrograman assembly dimana berbagai fasilitas dengan fungsi masing-masing telah disediakan sehingga memudahkan pengguna untuk merangkai dengan hubungan kabel dengan mudah dan cepat.

Di dalam program LabVIEW terdapat dua tampilan yaitu tampilan Front Panel berfungsi untuk memperlihatkan fungsi setting, data yang tercatat dan berbagai macam grafik serta tombol fungsi seperti tombol on/off, start/stop dan lain-lain, kemudian tampilan yang kedua adalah Bolck Diagram berfungsi untuk merangkai berbagai macam fungsi komponen, data masukan/keluaran, pengkabelan, pengiriman data dan sebagaianya seperti terlihat pada Gambar 2.

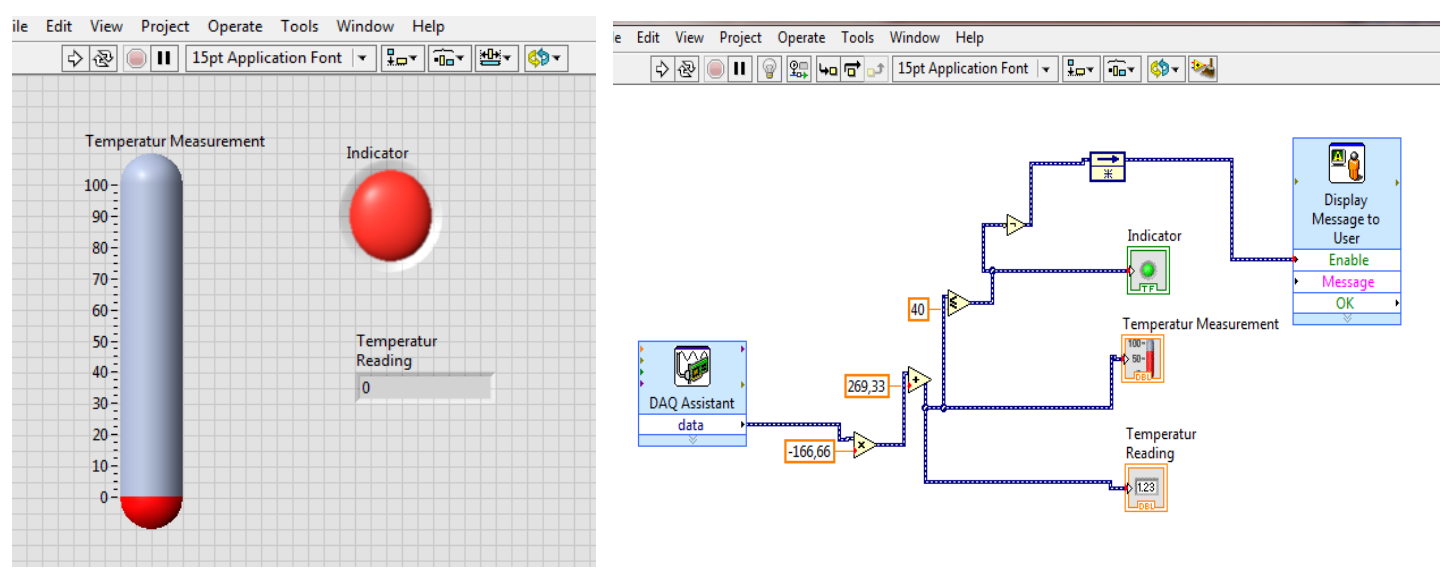

Gambar 2. Tampilan Front Panel Dan Block Diagram Labview

Proses pengolahan data analog yang dihasilkan oleh beberapa sensor yang digunakan pada chassis dynamometer type menjadi data digital agar bisa dibaca oleh software LabVIEW menggunakan Data Aquisition (DAQ) Produk National Instrument (NI) tipe USB 6008. Perangkat DAQ NI USB 6008 merupakan salah satu jenis pengolah data yang dapat dipakai untuk melakukan pengolahan data penelitian sehingga mendapatkan hasil yang diharapkan, memiliki beberapa keunggulan seperti tersedianya terminal Analog Input, Analog Output, Digital Input/Output dan lain sebagainya sehingga memudahkan penggunaan dalam pengambilan data serta memiliki beberapa fasilitas yang dapat langsung digunakan seperti untuk pengukuran Voltage DC, Current AC, Resistant Signal dan lain-lain [6].

\section{METODOLOGI PENELITIAN}

Kemampuan kerja suatu motor bakar diperoleh dengan melakukan pengukuran pada keluaran dari kerja motor bakar pada komponen poros engkol (crankshaft) berupa data Torsi dan Daya motor bakar. Seiring dengan perkembangan teknologi maka pengambilan data Torsi dan Daya serta data yang lain dilakukan dengan melakukan pengukuran pada komponen yang lain seperti yang penulis lakukan adalah dengan melakukan pengukuran pada kabel busi tegangan tinggi dengan menggunakan sensor tipe induksi untuk mengetahui jumlah putaran per menit komponen crankshaft, pengukuran pada bagian roda belakang yang memutarkan sebuah roller untuk mengetahui besaran momen inertia yang akan digunakan dalam suatu persamaan untuk perhitungan data Torsi serta pengukuran menggunakan sensor temperatur untuk digunakan menghitung perbandingan bahan bakar dan udara (air fuel ratio).

Pelaksaan kegiatan penelitian ini memanfaatkan penggunaan beberapa komponen seperti beberapa jenis sensor seperti sensor putaran jenis induksi proximity [10], sensor temperatur dan sensor induksi tegangan tinggi, komponen penguat tegangan pada sensor, komponen pengolah data aquisition jenis $N I$ DAQ USB 6008 seperti terlihat pada Gambar 3, program LabVIEW, sumber tegangan listrik dan komponen pembaca sensor sebagai pembanding keluaran data dari keluaran program yang dibuat, perangkat laptop untuk pembuatan program LabVIEW dan satu unit motor bakar berbahan bakar bensin 4 langkah yang terpasang pada sepeda motor serta satu unit chassis dynamometer type roller and inertia. 


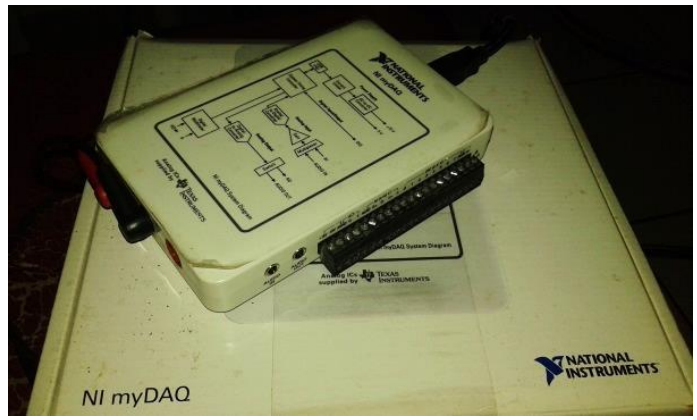

\section{Gambar 3. Perangkat Data Aquisition Usb 6008 Produk National Instrument}

Proses pengambilan data indikator kinerja motor bakar berbahan bakar bensin dilakukan dengan mengukur putaran pada komponen roda yang menapak pada roller dynamometer seperti terlihat pada Gambar 4, sedangkan pengukuran putaran output motor bakar pada komponen kabel tegangan tinggi ke busi menggunakan sensor jenis induksi dan pengukuran temperatur ruang uji dilakukan menggunakan sensor temperatur jenis thermocouple tipe $\mathrm{K}$.
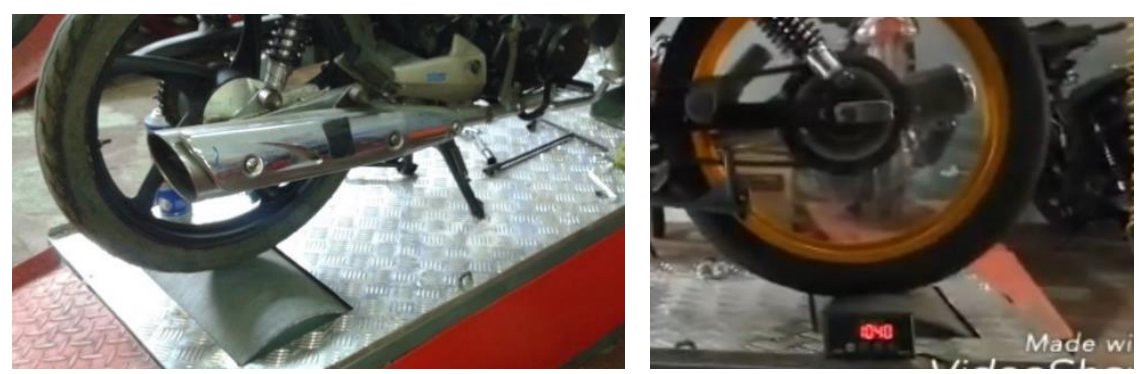

Gambar 4. Pengujian Komponen Sensor RPM Pada Roller

Flowcart kegiatan penelitian dimulai dengan studi pustaka dan diakhiri dengan kesimpulan, secara detail dapat dilihat pada Gambar 5.

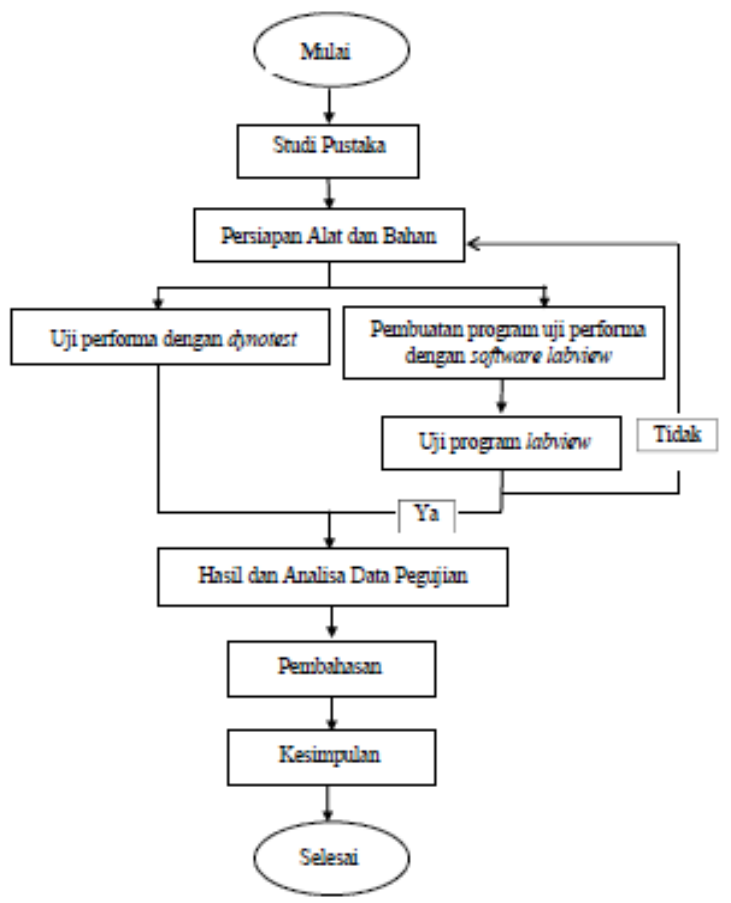

Gambar 5. Flowcart Kegiatan Penelitian

Proses pengambilan data pada saat pengujian dilakukan dengan memberikan putaran pada roller dynamometer dengan cara membuka katup gas (throttle valve) mulai putaran stasioner sampai putaran 
tertinggi, pada roller dynamometer yang digunakan pembacaan putaran dimulai pada putaran sekitar 3000 Rpm sampai putaran tertinggi.

\section{HASIL DAN PEMBAHASAN}

Hasil dari pengambilan data pengujian pada motor bensin didapat seperti terlihat pada Gambar 6 .

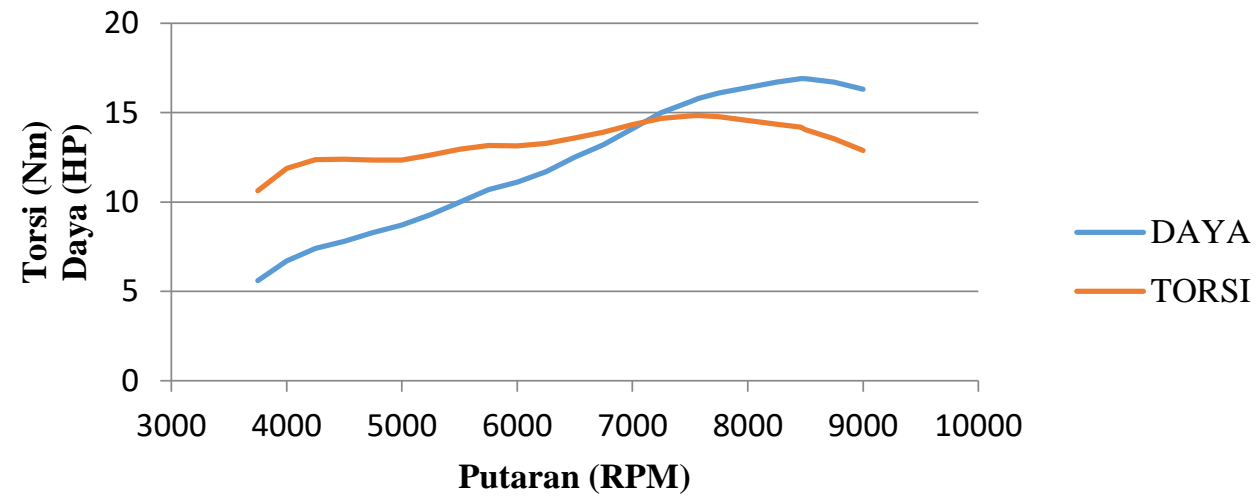

\section{Gambar 6. Grafik Hasil Pengukuran Torsi Dan Daya Menggunakan Roller Dynamometer Type}

Pengambilan data performa motor bensin saat pengujian menggunakan Roller Dynamometer tipe inersia dan pengolahan data berbasis program LabVIEW dengan beberapa sensor sebagai masukan kemudian diolah menggunakan beberapa persamaan matematik mendapatkan data-data sebagai berikut data Torsi mulai terbaca pada putaran 3750 RPM dengan nilai sekitar 10,65 Nm dan mencapai nilai maksimal pada putaran 7574 RPM dengan nilai Torsi sebesar 14,84 Nm dan setelahnya akan mengalami penurunan, hal ini sesuai dengan karakteristik yang dimiliki oleh performa motor bensin [1]. Data Daya yang diperoleh dari pengujian mulai terbaca pada putaran 3750 RPM dengan nilai sebesar 5,6 HP dan mencapai nilai maksimal pada putaran 8500 RPM dengan nilai sebesar 16,9 HP. Beberapa hasil penelitian yang sejenis juga memperlihatkan hasil yang serupa hal ini menunjukan bahwa penggunaan perangkat lunak dan pengolahan data dengan persamaan matematik dapat digunakan sebagai alat bantu para peneliti sehingga data-data dapat diperoleh secara real time. Beberapa hal yang perlu diperhatikan pada saat pembuatan program LabVIEW agar hasil data yang diperoleh valid seperti pemilihan fungsi pada program LabVIEW, penggunaan referensi persamaan matematik harus disesuaikan dengan dimensi jenis dynamometer yang digunakan, faktor lingkungan dan jenis sensor yang digunakan. Hal lain yang dapat mempengaruhi data hasil pengujian adalah operator saat pengambilan data terdapat perbedaan hasil saat dilakukan oleh operator yang belum dan sudah berpengalaman seperti memulai pencatatan data pada saat pengujian.

\section{KESIMPULAN}

Dari beberapa proses pengambilan data dan pengolahan menggunakan data aquisition tipe DAQ USB 6009 produk National Instrument, software LabVIEW dan beberapa jenis sensor memperoleh hasil data karakteristik motor bensin seperti pada umumnya yaitu grafik data Torsi dan Daya mengalami kenaikan seiring dengan putaran crankshaft dan setelah mencapai puncaknya akan mengalami penurunan, hasil tersebut menggambarkan bahwa pengambilan data dan pengolahan data menggunakan software LabVIEW dalam penelitian ini memiliki gambaran grafik tidak berbeda jauh dengan pengujian serupa menggunakan data aquisition produk pabrikan (build up dynamometer).

\section{UCAPAN TERIMA KASIH}

a. Kemenristek Dikti melalui Direktorat Riset dan Pengabdian Masyarakat, Direktorat Jenderal Penguatan Riset dan Pengembangan, Kementerian Riset, Teknologi, dan Pendidikan Tinggi yang telah membiayai kegiatan penelitian melalui skema Penelitian Dosen Pemula.

b. Sekolah Tinggi Teknik Wiworotomo Purwokerto melalui P3M dan Program Studi Teknik Mesin yang telah mensuport selama kegiatan penelitian. 


\section{DAFTAR PUSTAKA}

[1] W. W. Pulkrabek, Engineering Fundamentals of The Internal Combustion Engine. .

[2] R. Johnsson, "Crankshaft Speed Measurements and Analysis for Control and engines," 2001.

[3] Alan S Morris, Measurement \$ Instrumentation Principles, Third. 2001.

[4] M. M. U. Awan, Z. Ali, N. Sultana, S. Ali, and A. Maroof, "Design and Construction of a Frictional Brake Absorption Dynamometer using Electrical Strain Gauges."

[5] V. J. Tharakan and J. P. Prasad, "Speed Control of the DC Motor through Temperature Variations using Labview and Aurdino," no. Vi, 2017.

[6] A. Mishra and P. Mishra, "Design Of Temperature Controllers Using Labview," 2013.

[7] S. Qomariah and Rahayu, "Sistem Pemantauan Suhu Demam Berdarah Secara Otomatis Dan Realtime Berbasis Labview 7.1," p. 6.

[8] H. Connections, "Temperature and Proximity Sensor Requirements."

[9] N. Eddy and V. Purabaya, "Analisis Getaran untuk Mengindentifikasi Gearmesh Pada Transmisi Roda Gigi Lurus Menggunakan Perangkat Lunak Labview,” vol. 9, pp. 168-173, 2007.

[10] E. Susilawati and Z. Kamus, "Pembuatan alat ukur kecepatan putar gear menggunakan sensor proximity induktif dan mikrokontroler arduino uno," vol. 10, pp. 9-13, 2017. 